Original studies

Somnologie $2019 \cdot 23: 17-28$

https://doi.org/10.1007/s11818-019-0196-6

Received: 20 November 2018

Accepted: 18 January 2019

Published online: 22 February 2019

(c) The Author(s) 2019

CrossMark

Maria Tafelmeier ${ }^{1}$ Marvin Knapp ${ }^{1} \cdot$ Simon Lebek $\cdot$ Bernhard Floerchinger ${ }^{2}$. Daniele Camboni' ${ }^{2}$ Sigrid Wittmann ${ }^{3} \cdot$ Marcus Creutzenberg $^{3}$. Florian Zeman ${ }^{4}$. Christof Schmid ${ }^{2}$. Lars S. Maier ${ }^{1} \cdot$ Stefan Wagner ${ }^{1} \cdot$ Michael Arzt $^{1}$

' Department of Internal Medicine II (Cardiology, Pneumology, and Intensive Care), University Medical Center Regensburg, Regensburg, Germany

${ }^{2}$ Department of Cardiothoracic Surgery, University Medical Center Regensburg, Regensburg, Germany

${ }^{3}$ Department of Anesthesiology, University Medical Center Regensburg, Regensburg, Germany

${ }^{4}$ Center for Clinical Studies, University Medical Center Regensburg, Regensburg, Germany

\title{
Rationale and design of the CONSIDER AF study
}

\section{Impact of sleep-disordered breathing on atrial fibrillation and perioperative complications in patients undergoing coronary artery bypass grafting surgery}

as arrhythmia, myocardial infarction, the need for revascularization procedures, and cardiac arrest $[3,8]$. Moreover, SDB is associated with a higher rate of respiratory complications such as pneumonia or acute respiratory distress syndrome (ARDS), as well as with prolonged intubation and mechanical ventilation [9-12]. Furthermore, the occurrence of postoperative delirium is higher in patients with SDB than in patients without SDB [13]. In a retrospective analysis of 100 patients undergoing elective CABG surgery, we could recently show that SDB-particularly OSA - was associated with a prolonged postoperative hospital stay, independent of known confounders [4].

Sa far, few prospective observational studies have addressed peri- and postoperative complications in patients with SDB undergoing cardiac surgery. Previous studies were limited by relatively small study populations and the fact that the severity and type of SDB were not taken into account [3, 13-16]. Because most studies did not include a multivariable regression analysis, the influence of potential confounders remains unclear $[10,14]$. Furthermore, long-term follow-up data are sparse.
The objectives of the present observational study are to evaluate the impact of SDB on the rate of major adverse cardiac and cerebrovascular events (MACCE) in patients undergoing elective CABG surgery. In addition, explorative analyses will allow specification of subgroups of patients with SDB with the highest risk for peri- and postoperative complications. The results of this study may contribute to designing interventional studies and to optimizing the preoperative risk assessment as well as the peri- and postoperative management of patients with and without SDB undergoing elective cardiac surgery. Moreover, the biomaterial sub-study may generate novel hypotheses and improve diagnosis and management of atrial fibrillation in SDB patients.

\section{Methods}

\section{Study patients}

The current prospective observational study, "Impact of sleep-disordered breathing on atrial fibrillation and perioperative complications in patients undergoing coronary artery bypass grafting surgery (CONSIDER AF)," is a single-center study designed to evaluate the impact of
Patients with SDB are more prone to developing cardiac complications, such 
Table 1 Inclusion and exclusion criteria

\section{Inclusion criteria}

Aged 18-85 years

Patients undergoing elective coronary artery bypass grafting surgery at the Department of Cardiac and Thoracic Surgery, University Hospital Regensburg

Written informed consent

\section{Exclusion criteria}

Preoperative use of inotropes/vasopressors or circulatory assist devices

Severe obstructive pulmonary disease

Patients on oxygen therapy, nocturnal positive airway pressure support, or mechanical ventilation

SDB on the rate of MACCE in patients undergoing elective $\mathrm{CABG}$ surgery at the University Medical Center Regensburg in Germany. Patients are screened for eligibility and informed consent is obtained from all eligible patients who are willing to participate in the study. Key inclusion and exclusion criteria are presented in • Table 1.

\section{Study design}

At visit 1 , variables that may influence perioperative risk, such as demographic characteristics, common comorbidities, medication use, laboratory data, and cardiac catheterization results, are assessed by means of an interview and the patients' clinical records. Moreover, visit 1 also includes standardized echocardiography and assessment of SBD the night prior to CABG surgery. Visit 2 comprises the perioperative data obtained during CABG surgery. Postoperative complications during the first 7 days after CABG surgery, such as respiratory complications and major pulmonary complications, hemodynamic instability, enzymatic myocardial injury and coronary revascularization procedures, MACCE, presence and treatment of atrial fibrillation, acute kidney injury, and incidence of delirium, are assessed at visit 3. Assessment of long-term outcomes (use of positive airway pressure therapy, presence and treatment of atrial fibrillation, myocardial infarction, stroke, surgical and non-surgical coronary revascularization procedures, quality of life) is conducted at visits 4, 5, and 6, at 60 days, 1 year, and 2 years following $\mathrm{CABG}$ surgery, respectively (• Fig. 1).
Recruitment was started in July 2016 and enrolment is expected to be completed in July 2021. As the duration of follow-up for each patient will be 2 years, data analysis will be finished by July 2023 and a final report will be available at the beginning of 2024. In advance, selected research questions may be analyzed in a purely exploratory manner, provided that data management is conducted according to the data handling plan described in the online supplement. In brief, the project proposal and statistical analysis plan need to be submitted to the steering committee for approval before any data analysis is performed.

\section{Standard clinical treatment}

Patients do not routinely receive any premedication prior to surgery . Induction and maintenance of anesthesia are at the discretion of the anesthesiologists. All patients receive postoperative treatment according to the fast-track recovery care protocol that aims at early extubation and prompt implementation of mobility and occupational therapy within the intensive (ICU) and intermediate care unit (IMC) settings [17, 18]. Patients are weaned from mechanical ventilation at the discretion of the ICU physicians. Recommended delirium-prevention strategies are implemented within the standard postoperative care of patients $[19,20]$.

\section{Study objectives}

The aim of the prospective observational study CONSIDER AF is to determine whether the rate of MACCE is higher and the occurrence of atrial fibrillation and perioperative complications more frequent in patients with SDB under- going elective CABG surgery compared to those without SDB. Primary and secondary objectives as well as the objectives of the accompanying biomaterial study are presented in $\bullet$ Table 2.

\section{Assessment of sleep-disordered breathing}

After enrolment into the study, SDB monitoring is performed during the night before CABG surgery. Nasal flow, pulse oximetry, and thoracic breathing effort are measured with the Alice NightOne device (Philips Respironics, Murrysville, PA, USA). As described previously [4], apnea is defined as $a \geq 80 \%$ decrease in airflow for $\geq 10 \mathrm{~s}$, hypopnea as a decrease in airflow by $\geq 50-80 \%$ versus baseline for $\geq 10$ s, and desaturation as a $\geq 4 \%$ decrease in oxygen saturation. The apnea-hypopnea index (AHI) is expressed as the frequency of apneas or hypopneas per hour of sleep, and an AHI of $\geq 15 / h$ is considered the cut-off for the diagnosis of SDB. Patients with SDB and $\geq 50 \%$ central apneas are classified into the CSA group and patients with $<50 \%$ central apneas into the OSA group.

By means of structured phone interviews at visits 4,5 , and 6 , the use of mandibular advancement devices, longterm oxygen therapy, or positive airway pressure treatment is assessed. Details on recommendation and prescription of SDB therapies as well as treatment adherence are systematically examined.

\section{Postoperative outcomes}

\section{MACCE and coronary revascular- ization procedures}

Primary endpoint is the first occurrence of any component of the composite endpoint MACCE including all-cause mortality, non-fatal myocardial infarction (MI), and non-fatal cerebrovascular event occurring during or after CABG surgery within a) 60 days (visits 2 to 4 ), b) 1 year (visit 5), and c) 2 years (visit 6 ) of CABG surgery. All-cause mortality is defined as occurrence of death from any cause.

Periprocedural MI (early, within $72 \mathrm{~h}$ of CABG) or late MI ( $>72 \mathrm{~h}$ after CABG) are defined in accordance with the up- 
M. Tafelmeier · M. Knapp · S. Lebek · B. Floerchinger · D. Camboni · S. Wittmann · M. Creutzenberg · F. Zeman · C. Schmid · L. S. Maier · S. Wagner · M. Arzt

\section{Rationale and design of the CONSIDER AF study. Impact of sleep-disordered breathing on atrial fibrillation and perioperative complications in patients undergoing coronary artery bypass grafting surgery}

\section{Abstract}

Background. The objectives of the CONSIDER AF (NCT02877745) observational study are to evaluate the impact of sleep-disordered breathing (SDB) on the rate of major adverse cardiac and cerebrovascular events in patients undergoing elective coronary artery bypass grafting (CABG) surgery. In addition, explorative analyses will allow specification of subgroups of patients with SDB with the highest risk for peri- and postoperative complications.

Methods. CONSIDER AF is a single-center study in patients with and without SDB undergoing elective CABG. The presence and type of SDB are assessed the night prior to CABG using portable SDB monitoring. SDB is defined as an apnea-hypopnea index $\geq 15 / h$. Biomaterials (atrial myocardium and blood cells) are systematically sampled. New-onset atrial fibrillation and peri- and postoperative complications are prospectively evaluated during the hospital stay and over a period of 2 years. The relationship between postoperative complications and SDB or covariables associated with postoperative complications in univariable analyses are determined by multivariable logistic regression. Moreover, length of hospital stay and time spent in the intensive/intermediate care unit (ICU/IMC) of patients with and without SDB are analyzed. The harvested biomaterials are analyzed for novel signaling events and biomarkers.
Discussion. The prospective observational CONSIDER AF study is needed to identify specific risks, including SDB, and risk populations in cardiac surgery. In addition, CONSIDER AF has the potential to generate the rationale for hypotheses regarding periand postoperative management of patients with SDB to be tested in future randomized clinical trials. Based on this knowledge, the peri- and postoperative management of patients with SDB may be optimized.

Keywords

Cardiac surgery · Risk factors · Coronary artery disease - Obstructive sleep apnea · Central sleep apnea

\section{Rationale und Design der CONSIDER-AF-Studie. Einfluss schlafbezogener Atmungsstörungen auf Vorhofflimmern und perioperative Komplikationen bei Patienten mit koronarer Bypass-Operation}

\section{Zusammenfassung}

Hintergrund. Ziel der vorliegenden Beobachtungsstudie CONSIDER AF (NCT02877745) ist es, den Einfluss schlafbezogener Atmungsstörungen (SDB) auf die Rate schwerer kardialer und zerebrovaskulärer Ereignisse bei Patienten nach elektiver aortokoronarer Bypassoperation (CABG) zu untersuchen. Mittels explorativer Analysen sollen zudem Subgruppen von SDB-Patienten mit dem höchsten Risiko für peri- und postoperative Komplikationen bestimmt werden.

Methoden. Die CONSIDER-AF-Studie ist eine Einzelzentrumsstudie bei Patienten mit und ohne SDB, bei denen eine elektive CABG-Op. geplant ist. In der Nacht vor der CABG-Op. wird mittels portablen SDB-Monitorings das Vorliegen bzw. der Typ einer SDB beurteilt.
Eine SDB ist definiert als Apnoe-HypopnoeIndex von $\geq 15 / h$. Biomaterial (Vorhofmyokard und Blut) wird systematisch gewonnen. Neu auftretendes Vorhofflimmern sowie peri- und postoperative Komplikationen werden prospektiv während der Verweildauer und dann 2 Jahre lang evaluiert. Der Zusammenhang zwischen postoperativen Komplikationen und SDB oder Kovariablen, die mit postoperativen Komplikationen in univariaten Analysen assoziiert sind, wird durch ein multivariables logistisches Regressionsmodell bestimmt. Außerdem werden Verweildauer und Zeit auf der Intensivstation von Patienten mit und ohne SDB untersucht. Das gewonnene Biomaterial wird auf neue Signalwege und Biomarker hin analysiert.
Schlussfolgerung. Zweck von CONSIDER $\mathrm{AF}$ ist die Erkennung spezifischer Risiken, einschließlich SDB, und Risikopopulationen in der Herzchirurgie. Darüber hinaus hat CONSIDER AF das Potenzial, Grundlagen für Hypothesen zum peri- und postoperativen Management von SDB-Patienten mit dem Ziel der Überprüfung in zukünftigen randomisierten klinischen Studien zu liefern. Auf Basis dieses Wissens kann das periund postoperative Management von SDBPatienten optimiert werden.

Schlüsselwörter Herzchirurgie · Risikofaktoren · Koronare Herzerkrankung · obstruktive Schlafapnoe · zentrale Schlafapnoe dated consensus statement of the European Society of Cardiology [21]. Briefly, early $\mathrm{MI}$ is indicated by troponin $\mathrm{I}(\mathrm{TnI})$ values $>10$ times the upper limit of normal (ULN; 99th percentile) when associated with one of the following criteria: new pathologic Q-waves, left bundle-branch block, angiographically documented new graft or native coronary artery occlusion, or imaging evidence of new loss of viable myocardium. Late
MI is defined as any new re-elevation of TnI from a previous nadir to over ULN with either pathologic Q-waves or ST-segment elevation. In patients undergoing a repeat revascularization procedure after primary surgery (percutaneous coronary intervention [PCI] or reCABG), MI will be diagnosed in the presence of documented new graft or new native coronary artery occlusion or imag- ing evidence of new loss of viable myocardium.

Non-fatal cerebrovascular events, i. e., stroke or transient ischemic attack (TIA), are defined in accordance with current guidelines of the American Stroke Association [22]. Stroke is defined as the presence of clinical signs of focal or global cerebral, spinal, or retinal neurologic dysfunction, and radiologic evidence of new brain infarction, as assessed by 


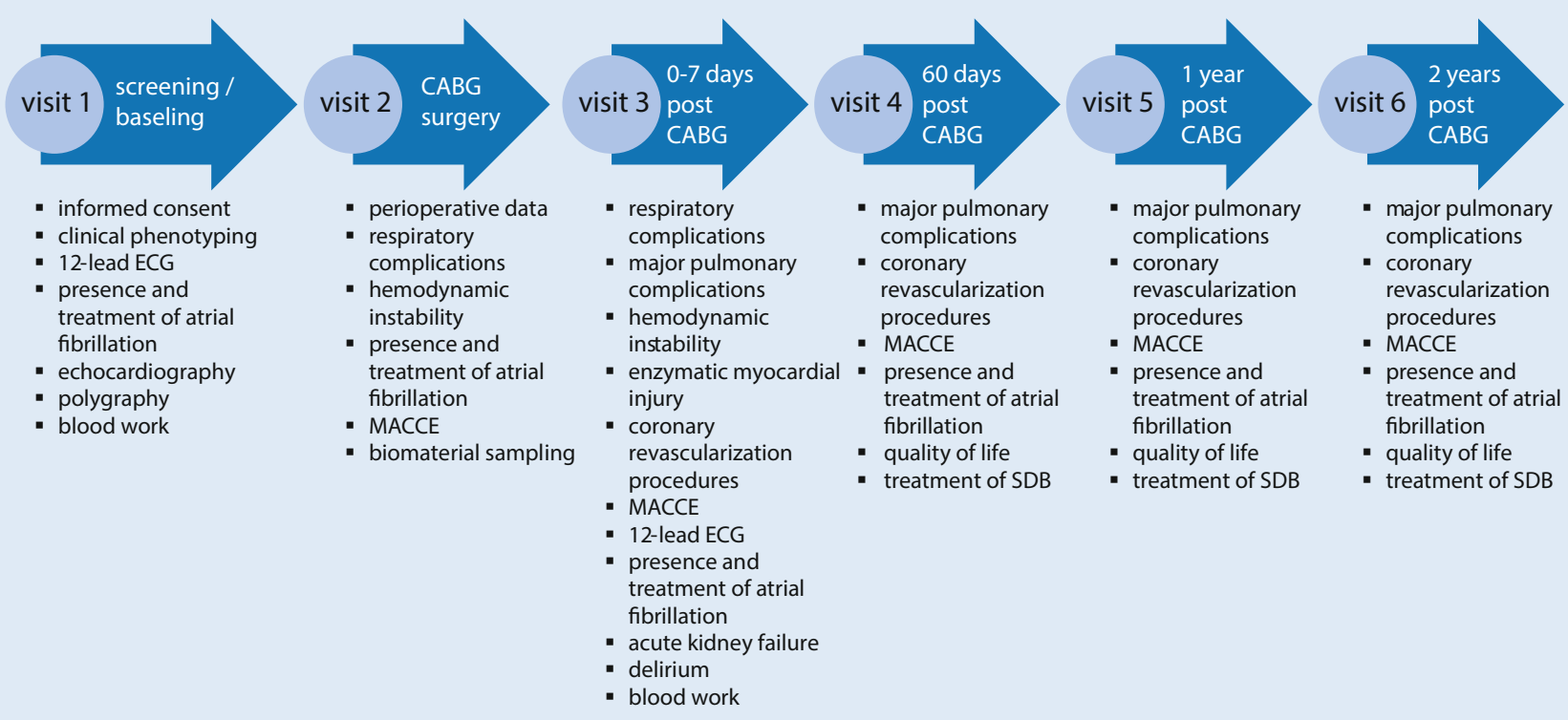

Fig. 1 Study design. CABG coronary artery bypass grafting, MACCE major adverse cardiac and cerebrovascular events, $S D B$ sleep-disordered breathing, ECG electrocardiography

computed tomography or magnetic resonance imaging, from CABG surgery through to 60 days, 1 year, or 2 years after CABG surgery. TIA is indicated as a transient episode of clinical signs of focal brain, spinal cord, or retinal ischemia typically lasting $<2 \mathrm{~h}$ without radiologic evidence of new brain injury.

To ascertain the above endpoints, quantitative measurement of TnI, creatine kinase (CK), and CK-muscle/brain (CK-MB) fraction as well as electrocardiograms and cerebral imaging reports are analyzed in a blinded manner by the clinical events committee. This process insures that events critical to the analysis of the study will be assessed in a uniform manner.

\section{Postoperative atrial fibrillation}

New-onset atrial fibrillation as detected within the postoperative phase is assessed by routine $24 \mathrm{~h}$ ECG monitoring. During the in-hospital phase after CABG surgery, initiation of pharmacologic therapy and electric cardioversion as well as anticoagulation therapy for treatment of atrial fibrillation is obtained from clinical records. At 60 days, 1 year, and 2 years after CABG surgery, assessment of pharmacologic therapy, cardioversion, and anticoagulation therapy for the treatment of atrial fibrillation is part of the structured phone interview. Medication for rhythm control of atrial fibrillation is recorded according to the Vaughan-Williams classification.

Moreover, the validated Atrial Fibrillation Effects on Quality of Life (AFEQT) questionnaire is provided for patients who are diagnosed with atrial fibrillation as part of the follow-up visits 60 days, 1 year, and 2 years after CABG surgery. Permission to use the AFEQT questionnaire was granted by the copyright holders. The AFEQT is a 20 -item survey using 7-point response scales, which measures atrial fibrillation-specific health status [23]. It quantifies four domains of patients' health status: symptoms, daily activities, treatment concern, and treatment satisfaction. The AFEQT scores range from 0 to 100 , with 100 representing the best possible health status and 0 representing the worst.

Within a subset of the CONSIDER AF population, continuous ECG monitoring with an automated atrial fibrillation detection algorithm is performed to detect atrial fibrillation in the earlyphase (1-7 days) post CABG. Patients are instructed to wear the monitor as much as possible for 7 days. All the episodes of atrial fibrillation are adjudicated by two cardiologists who are unaware of the patient's demographic and clinical charac- teristics, and any disagreements are resolved by discussion with an independent cardiologist. Results are sent to the family physician of the patient, and decisions regarding anticoagulant therapy are made at the discretion of the treating physicians.

\section{Major pulmonary and respiratory complications}

Endotracheal intubation is rated as difficult in the presence of poor visualization of the glottis (Cormack and Lehane grade III or IV), when an intubation aid (stylet, intubating laryngeal mask airway, fiberoptic bronchoscope) is needed, or when three or more intubation attempts are required [24]. Peri- and postoperative hypoxemia is considered present if the patient develops oxygen desaturations $<90 \%$ for or with a $\geq 4 \%$ reduction from the last recorded preoperative value. Postoperative respiratory failure is defined as a need for prolonged mechanical ventilation for $\geq 24 \mathrm{~h}$ or a need for endotracheal reintubation or tracheostomy [10]. ARDS, pneumonia, or pulmonary embolism represent major pulmonary complications. Diagnosis of ARDS is made according to the Berlin Definition [25] by an acute onset within 1 week of $\mathrm{CABG}$, bilateral opacities on chest imaging, an $\mathrm{PaO}_{2} / \mathrm{FiO}_{2}<300 \mathrm{~mm} \mathrm{Hg}$, 
Table 2 Primary and secondary objectives

\section{Primary objective}

To determine whether patients with SDB have a higher rate of MACCE as measured by the first occurrence of any component of the composite primary endpoint of all-cause mortality, nonfatal MI, and nonfatal cerebrovascular event (stroke or TIA) occurring within 60 days after CABG surgery compared to those without SDB

\section{Secondary objectives}

To determine whether the rate of postoperative atrial fibrillation is higher in patients with SDB within 60 days, 1 year, and 2 years after CABG surgery compared to those without SDB.

To determine whether the occurrence of postoperative stroke is more frequent in patients with SDB within 60 days, 1 year, and 2 years after CABG surgery compared to those without SDB.

To determine whether SDB patients have a higher rate of MACCE within 60 days, 1 year, and 2 years after $C A B G$ surgery compared to those without SDB.

To determine whether SDB patients have a higher rate of major pulmonary complications within 60 days, 1 year, and 2 years (including pneumonia, respiratory insufficiency, and pulmonary embolism) after CABG surgery compared to those without SDB.

To determine whether the rate of peri- and postoperative respiratory complications (difficult intubation, hypoxemia, respiratory failure, use of extracorporeal mechanical oxygenation device) is higher in patients with SDB compared to those without SDB.

To determine whether the rate of peri- and postoperative hemodynamic instability and heart failure is higher in patients with SDB compared to those without SDB.

To determine whether the rate of postoperative enzymatic myocardial injury is higher in patients with SDB compared to those without SDB.

To determine whether the rate of postoperative acute kidney injury is higher in patients with SDB compared to those without SDB.

To determine whether the rate of postoperative delirium is higher in patients with SDB compared to those without SDB.

To determine whether patients with SDB have an impaired general (EuroQol, Atrial Fibrillation Effect on Quality of Life, Seattle Angina Questionnaire) and disease-specific quality of life compared to those without SDB

\section{Objective of the biomaterial study}

To determine key signaling events in atrial myocardium that may predispose to atrial fibrillation To assess potential biomarkers in serum or blood cells (PBMCs) that help to identify patients at risk for atrial fibrillation

To foster the development of novel drug targets for SDB patients

SDB sleep-disordered breathing, MACCE major adverse cardiac and cerebrovascular events, $M I$ myocardial infarction, TIA transient ischemic attack, CABG coronary artery bypass grafting, PBMCs peripheral blood mononuclear cells

and exclusion of heart failure or volume overload. Postoperative use of an extracorporeal mechanical oxygenation device (ECMO) is registered. Pneumonia is diagnosed by a combination of physical signs (fever, putrid sputum, vital signs), radiologic findings, and/or microbiologic cultures. Early postoperative pneumonia (day 0-7) is differentiated from pneumonia occurring with greater latency. By means of structured phone interviews and detailed information from the patients' medical records, major pulmonary complications are additionally assessed at visits 4,5 , and 6 .

\section{Hemodynamic instability and acute heart failure}

Hemodynamic instability due to any cause is defined as a need for vasopressors or inotropes (epinephrine, norepinephrine, dobutamine, and milrinone) for $\geq 48 \mathrm{~h}$ postoperatively. Postoperative acute heart failure is defined as new pulmonary edema, increased of use of diuretic or afterload/preload reducing agents, or physician's documentation of acute heart failure. Postoperative use of circulatory assist devices is recorded.

\section{Postoperative enzymatic myocardial injury and coronary revascularization procedures}

Evaluation of perioperative enzymatic myocardial injury, as measured by the perioperative release of TnI and CK-MB, is performed by analysis of serial blood samples. These markers have been found to be predictive of major cardiac events after CABG surgery [26, 27]. Serial blood samples are drawn on admission (1) to the surgical ICU and at 4-10 (2) and 14-24 (3) hours after surgery according to clinical routine. Levels of serum TnI are measured with luminescence oxygen channeling immunoassay. The highest $\mathrm{TnI}$ value during the first $24 \mathrm{~h}$ was taken as peak TnI. At visits 3 to 6 , coronary revascularization procedures are assessed and ascertained by the Clinical Events Committee using the patients' clinical records and medical reports.

\section{Postoperative acute kidney injury}

Postoperative acute kidney injury (AKI) is defined according to the Kidney Disease Improving Global Outcomes (KDIGO) Foundation guideline [28]. As KDIGO recommends staging AKI according to its severity, stage 1 is defined as increased serum creatinine $\geq 1.5$ to 1.9 times the baseline value or $\geq 0.3 \mathrm{mg} / \mathrm{dl}$ from baseline or urine output $<0.5 \mathrm{ml} / \mathrm{kg}$ per hour for $6-12 \mathrm{~h}$; stage 2 is defined as increased serum creatinine $\geq 2.0$ to 2.9 times the baseline value or urine output $<0.5 \mathrm{ml} / \mathrm{kg}$ per 
hour for $12 \mathrm{~h}$; and stage 3 is defined as increased serum creatinine $\geq 3$ the baseline value or $\geq 4 \mathrm{mg} / \mathrm{dl}$ or initiation of renal replacement therapy, or urine output $<0.3 \mathrm{ml} / \mathrm{kg}$ per hour for $24 \mathrm{~h}$ or

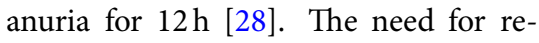
nal replacement therapy is specified as temporary or permanent (in case the patient dies or is discharged on renal replacement therapy).

\section{Assessment of postoperative delirium}

Delirium is assessed once a day using the Confusion Assessment Method for the Intensive Care Unit (CAM-ICU) [29]. The CAM-ICU is a valid and reliable delirium assessment tool that has shown high sensitivity (93\%) and specificity (89\%) for the diagnosis of delirium [30] and is recommended by the American College of Critical Care Medicine [31]. The CAM-ICU scores are obtained by trained medical staff on the day of extubation and for a maximum of 3 days. Before CAM-ICU assessment, the sedative state is evaluated as a standard feature using the Richmond Agitation and Sedation Scale (RASS) [32, 33]. In patients with deep sedative stages, rated as a RASS score of -4 or -5 , evaluation is omitted.

\section{Assessment of quality of life}

In order to assess general and diseasespecific quality of life, the validated and self-administered questionnaires EuroQuol 5D (EQ-5D) and Seattle Angina questionnaire (SAQ) are distributed by mail as part of the follow-up visits 60 days, 1 year, and 2 years after CABG surgery. Permissions to use the EQ-5D and SAQ questionnaires were obtained from the copyright holders.

The EQ-5D questionnaire has five dimensions focusing on mobility, selfcare, usual activities, pain/discomfort, and anxiety/depression [34]. Each dimension has three levels: no problems (no limitations), some problems, and severe problems. Furthermore, general health status is measured on a visual analog scale (VAS) in which 0 denotes the worst imaginable health state and 100 the best imaginable health state.
The SAQ is a 19-item questionnaire measuring five dimensions of health status: exertional capacity, anginal stability, anginal frequency, treatment satisfaction, and quality of life, generating five independent scales [35]. Each question is measured on an ordinal scale from 1 to 5 (6 for the angina frequency scale), with 1 indicating the lowest/poorest response and 5/6 indicating the highest/best response.

\section{Biomaterial sampling}

Right atrial appendage biopsies are received from patients during elective CABG [36]. Biopsies are transported in ice-cold Custodiol ${ }^{\circledR}$ (Essential Pharmaceuticals, LLC, Durham, NC, USA) solution containing $2 \mathrm{mmol} / \mathrm{L}$ butanedione monoxime (BDM) for cardioplegia to our laboratories. Upon arrival, human biopsies are immediately frozen and stored in a tissue biobank at $-80^{\circ} \mathrm{C}$. Tissue is used for measurement of protein or gene expression by western blotting or PCR, respectively. Besides tissue samples, blood samples are taken from the patients immediately before surgery and used for isolation of peripheral blood mononuclear cells (PBMCs). The PBMCs are rapidly frozen and stored in a liquid biobank at $-80^{\circ} \mathrm{C}$. The remaining blood plasma is also collected and stored separately in the liquid biobank. It is planned to analyze PMBCs for gene expression by PCR or fluorescence-activated cell scanning (FACs). Plasma samples are analyzed for the presence of oxidized low-density lipoproteins. For some experiments, atrial biopsies are also used immediately for assessment of contractile function, arrhythmias, intracellular $\mathrm{Ca}$ and $\mathrm{Na}$ ion handling, and whole-cell patch clamp electrophysiology (ion currents and membrane potential). Briefly, human atrial trabeculae are microdissected and mounted onto a force transducer in an organ bath. Contraction is elicited by electrical field stimulation and the developed mechanical force is recorded. Besides contractility measurements, premature atrial contractions (PACs) are analyzed as a surrogate for atrial arrhythmias. In separate experiments, human atrial cardiomyocytes are isolated from tissue by chunk isolation [36]. Isolated atrial cardiomyocytes are plated onto laminincoated measurement chambers, loaded with fluorescence dyes for assessment of intracellular $\mathrm{Ca}$ (Fluo-4, $10 \mu \mathrm{mol} / \mathrm{L}$ ) or $\mathrm{Na}(\mathrm{SBFI}, 10 \mu \mathrm{mol} / \mathrm{L})$, and mounted on the stage of either epifluorescence microscopes (IonOptix Limited, Dublin, Ireland) or a confocal microscope (Zeiss LSM 700; Zeiss, Oberkochen, Germany). Some cardiomyocytes are used for measurement of sarcolemmal ion currents and membrane potential by whole-cell patch clamp (HEKA Elektronik Dr. Schulze GmbH, Lambrecht/ Pfalz, Germany).

\section{Statistical analysis}

Statistical analyses will be performed using SPSS software version 24.0 or higher (IBM SPSS Statistics, Armonk, New York, USA). Data will be described as mean and standard deviation for normally distributed data, as median (25th;75th percentile) for non-normally distributed data, and as numbers and percentages for categorical variables. The normality of data distribution will be determined using the Kolmogorov-Smirnov test. Differences in baseline characteristics, nocturnal respiration data, and outcome variables between patients with and without SDB (analysis population I) or patients with different severities and types of SDB (analysis populations II and III) will be compared using analysis of variance (ANOVA) for normally distributed continuous variables, the Kruskal-Wallis test for nonnormally distributed continuous variables and the Persons chi-square test for categorical variables. A two-sided $p$ value of $\leq 0.05$ will be considered statistically significant for all analyses.

Primary endpoint. A multivariable logistic regression model with the primary target variable MACCE within 60 days after $\mathrm{CABG}$ (no/yes) as the dependent variable and SDB (no/yes), age, body mass index (BMI), sex (male/female), heart failure (no/yes), and diabetes mellitus (no/yes) as independent variables will be carried out in order to test the null hypothesis 


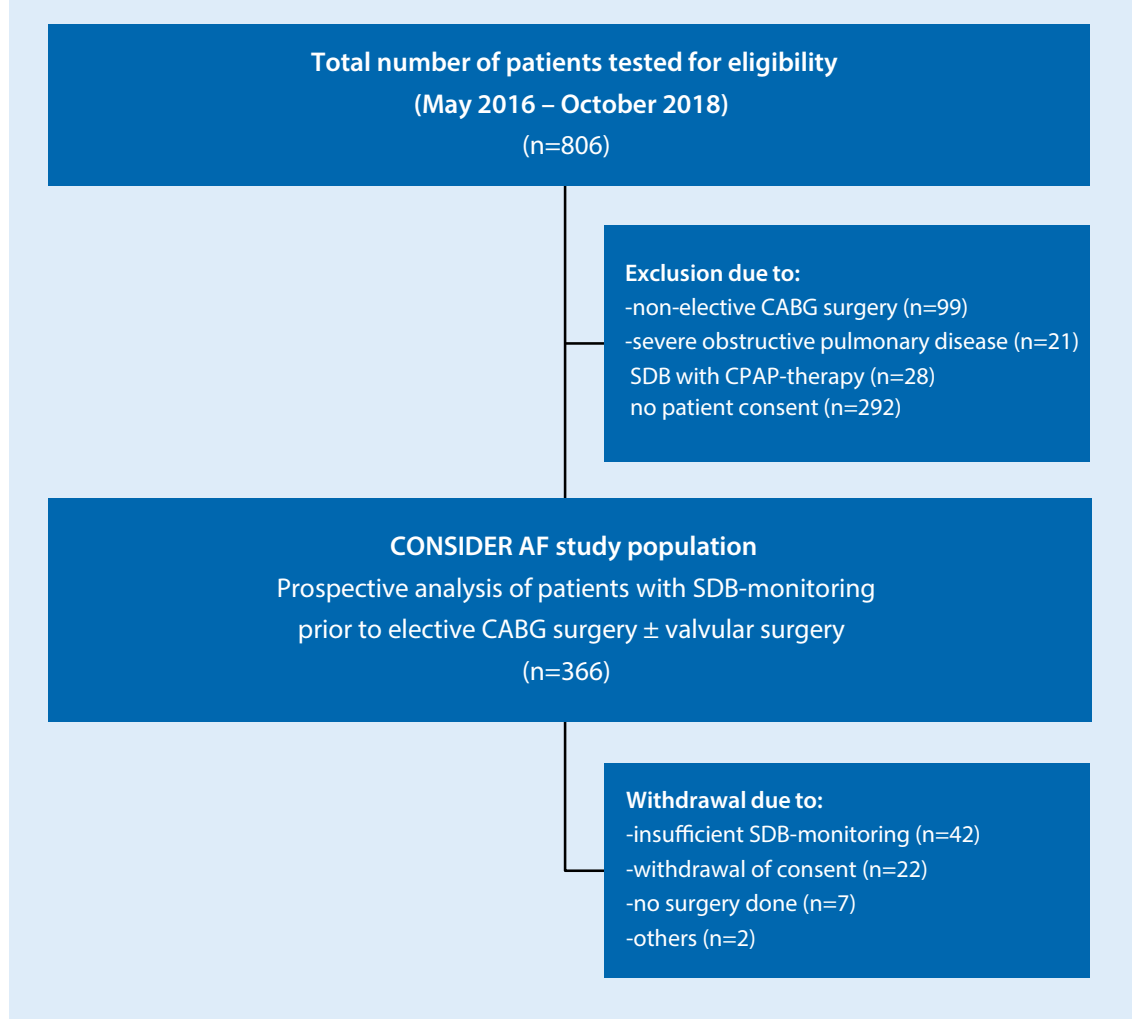

Fig. $2 \Delta$ Study flowchart. $S D B$ sleep-disordered breathing, $C A B G$ coronary artery bypass grafting

H0: $\mathrm{OR}_{\mathrm{SDB}}=1$ (i. e., there is no difference between patients with SDB and without SDB regarding MACCE) at a two-sided $5 \%$ significance level. For the odds ratio (OR), a point estimate and a two-sided $95 \%$ confidence interval will be provided.

Secondary endpoints. The risk of patients without SDB and with untreated and treated SDB for long-term outcomes such as the rate of MACCE will be calculated using multivariable Cox proportional hazard analysis. All secondary endpoints will be analyzed in a purely exploratory manner and summarized by means of descriptive statistics. Thus, $p$ values and corresponding confidence intervals are descriptive in nature. Safety variables will be analyzed descriptively.

\section{Sample size calculation}

Sample size was calculated by means of the primary endpoint, i.e., MACCE within 60 days after CABG. The MACCE rate within 60 days is assumed to be $7 \%$ in the no SDB and $13 \%$ in the SDB group according to a recently published study $\geq 15 / \mathrm{h}$ ) was $37 \%$. Alpha (two-sided) was set to 0.05 and beta was set to 0.80 (power 80\%).

To detect an odds ratio of 1.99 (patients with SDB vs. patients without SDB) with a prevalence of SDB of $37 \%$ with $80 \%$ power at a two-sided significance level of 0.05 , a total of 815 patients are required. This calculation is based on a simple method of sample size calculation for logistic regression proposed by Hsieh et al. [37]. Since we expect confounding of the results by the covariates age, BMI, sex, heart failure, and diabetes mellitus, the primary analysis will be done using a multivariable logistic regression model. This may inflate the variance of the estimated parameter and thus reduce the power to detect the estimated effect. Therefore, the sample size will be adjusted by a conservative approach, dividing the sample size by the variance inflation factor (VIF) defined as $1-R^{2}$, where $R^{2}$ is the squared multiple correlation coefficient of the primary variable with the other covariates. The squared multiple correlation coefficient $\mathrm{R}^{2}$ of $\mathrm{AHI}$ versus the other covariates was estimated to be 0.2 in our retrospective pilot data. Hence, the final sample size is $n=815 /(1-0.2)=1019$ for fitting a multivariable logistic regression model. The sample size was calculated using R 3.2.1 (R Foundation for Statistical Computing, Vienna, Austria; http://www.R-project. org/).

According to a pilot analysis, we anticipate the failure rate to record a valid polygraphy to be $6 \%(n=72)$ and the lostto-follow-up rate to assess the primary endpoint MACCE at 60 days to be $8 \%$ $(n=96)$. Thus, 1200 participants have to be enrolled in the study in order to include 1019 participants in the analysis.

\section{Ethics and monitoring}

Approval for this prospective observational study was granted by the Ethics Committees of the University of Regensburg (no. 15-101-0238). The study is conducted within the principles of Good Clinical Practice and in accordance with the Declaration of Helsinki.

\section{Results}

By October 2018, a total of 366 patients had been recruited into the ongoing CONSIDER AF study. Of these patients, 31 were excluded, preponderantly due to withdrawal of consent or same-day cancellation of CABG surgery. As their SDB monitoring was insufficient, 42 patients were omitted from the analysis. To date, the final CONSIDER AF analysis cohort consists of 293 patients who can be classified according to the presence and type of SBD (• Fig. 2).

\section{Discussion}

In recent years, SDB has been increasingly recognized as an independent risk factor for the development of postoperative complications and a prolonged length of hospital stay after cardiac surgery. The prospective observational study CONSIDER AF may extend previous research 
in a number of ways (- Table 3): firstly, a very large patient cohort as targeted in CONSIDER AF will provide robust analyses of perioperative complications in patients with SDB undergoing elective CABG surgery compared to those without SDB. Secondly, CONSIDER AF aims at investigating postoperative outcome in patients undergoing elective $\mathrm{CABG}$ surgery with and without SDB in a comprehensive manner, comprising cardiac, respiratory, and renal complications, as well as length of hospital stay. Long-term follow-up will monitor patients for a period of 2 years following elective CABG surgery. Thirdly, new-onset postoperative atrial fibrillation is detected by continuous ECG monitoring within a subset of patients and atrial fibrillation-associated symptoms and complications are systematically assessed during long-term follow-up. Potential pathogenetic mechanisms of postoperative atrial fibrillation at the cellular and multicellular level are expansively studied using human biomaterial (right atrial appendage biopsies, blood samples). Moreover, potential myocardial mechanisms will also be investigated in patient-specific PBMCs. The latter may be important to identify potential biomarkers that are suitable for clinical assessment in patient cohorts for which no atrial biopsies are available. Finally, in contrast to previous studies, the type and severity of SDB are preoperatively assessed using SDB monitoring, which offers a more thorough understanding of the potentially differential impact of OSA and CSA on adverse outcome.

\section{Sample size}

Previous studies on adverse outcome in patients with SDB undergoing cardiac surgery are limited by relatively small study populations comprising less than 250 patients (• Table 3; [3, 4, 11, 13-15, 38]. However, in order to analyze SDB as a potential modulator of new-onset atrial fibrillation and peri- and postoperative complications using multivariable regression models, a large patient cohort with a sufficient number of SDB cases is required. Since the present prospective observational study CONSIDER AF aims at enrolling 1200 patients, interpretation of the association between SDB and periand postoperative complications can be done in a meaningful way.

\section{Assessment of postoperative outcomes}

Recently, diagnosis of SDB with an AHI of $\geq 15 /$ h was shown to be independently associated with length of hospital stay, prolonging hospitalization by 4 days in patients with OSA compared to patients without SDB [4]. This finding was consistent with a previous study by Bhama et al. [15], in which the diagnosis of OSA significantly increased length of hospital stay after CABG from 13 to 24 days. Moreover, patients with SDB had a higher incidence of postoperative hemodynamic instability [4], a higher incidence of MACCE, and were more prone to repeated revascularization procedures and typical angina [3]. Patients with SDB needed mechanical ventilation longer than patients without SDB $[4,14$, 15] and were more likely to develop respiratory complications, e.g., pneumonia or acute respiratory distress syndrome [9]. Patients with SDB are more prone to developing cardiac complications, such as arrhythmia, myocardial infarction, the need for revascularization procedures, and cardiac arrest $[3,8]$. Moreover, SDB is associated with a higher rate of respiratory complications such as pneumonia or ARDS as well as with prolonged intubation and mechanical ventilation [9-12]. Furthermore, the occurrence of postoperative delirium is higher in patients with SDB than in patients without SDB $[10,13]$.

While previous studies only focused on certain postoperative complications (- Table 3), CONSIDER AF covers a wide range of outcome parameters and aims at analyzing the impact of SDB on postoperative complications in a comprehensive manner. Moreover, not only short-term, but also long-term complications over a period of 2 years are investigated.

\section{Assessment of postoperative atrial fibrillation}

The present study will extend previous findings by evaluating the incidence of new-onset postoperative atrial fibrillation after elective CABG surgery in a sizable patient cohort with and without SDB. In a small-scale study by Uchôa et al. addressing the impact of OSA on new cardiovascular events in patients undergoing CABG surgery, newly diagnosed atrial fibrillation was more common in patients with than without OSA (22 vs. $0 \%, p<0.01$ ) in long-term follow-up [3]. This association between atrial fibrillation and OSA may be related to common risk factors and a mutually perpetuating pathophysiologic relationship between these conditions. Besides this, OSA promotes atrial fibrillation via electric and structural atrial remodeling [39].

In the present study, new-onset atrial fibrillation as detected within the postoperative clinical routine and its standard treatment are systematically assessed. Unlike in previous studies, continuous ECG monitoring is performed within a subset of the CONSIDER AF population to detect subclinical events of atrial fibrillation. Symptoms and severe complications arising from atrial fibrillation, e.g., stroke or TIA, are evaluated in the long-term follow-up. Moreover, a unique and distinguishing feature of our prospective observational study is the systematic sampling of human biomaterials (right atrial appendage biopsies and blood samples) that allow further assessment of potential pathogenetic mechanisms of postoperative atrial fibrillation at the cellular and multicellular level. The latter could also lead to identification of novel blood biomarkers which may improve SDB diagnostics and help identify patients at risk of atrial arrhythmias.

\section{Assessment of SDB and its subtypes}

As a major limitation of previous studies addressing postoperative complications in patients with SDB undergoing cardiac surgery, there is little information available on the adverse impact of CSA on patients' outcome. However, a significant proportion of CABG patients must be assumed to have CSA, as one third of these patients suffer from heart failure with a reduced ejection fraction [40] 


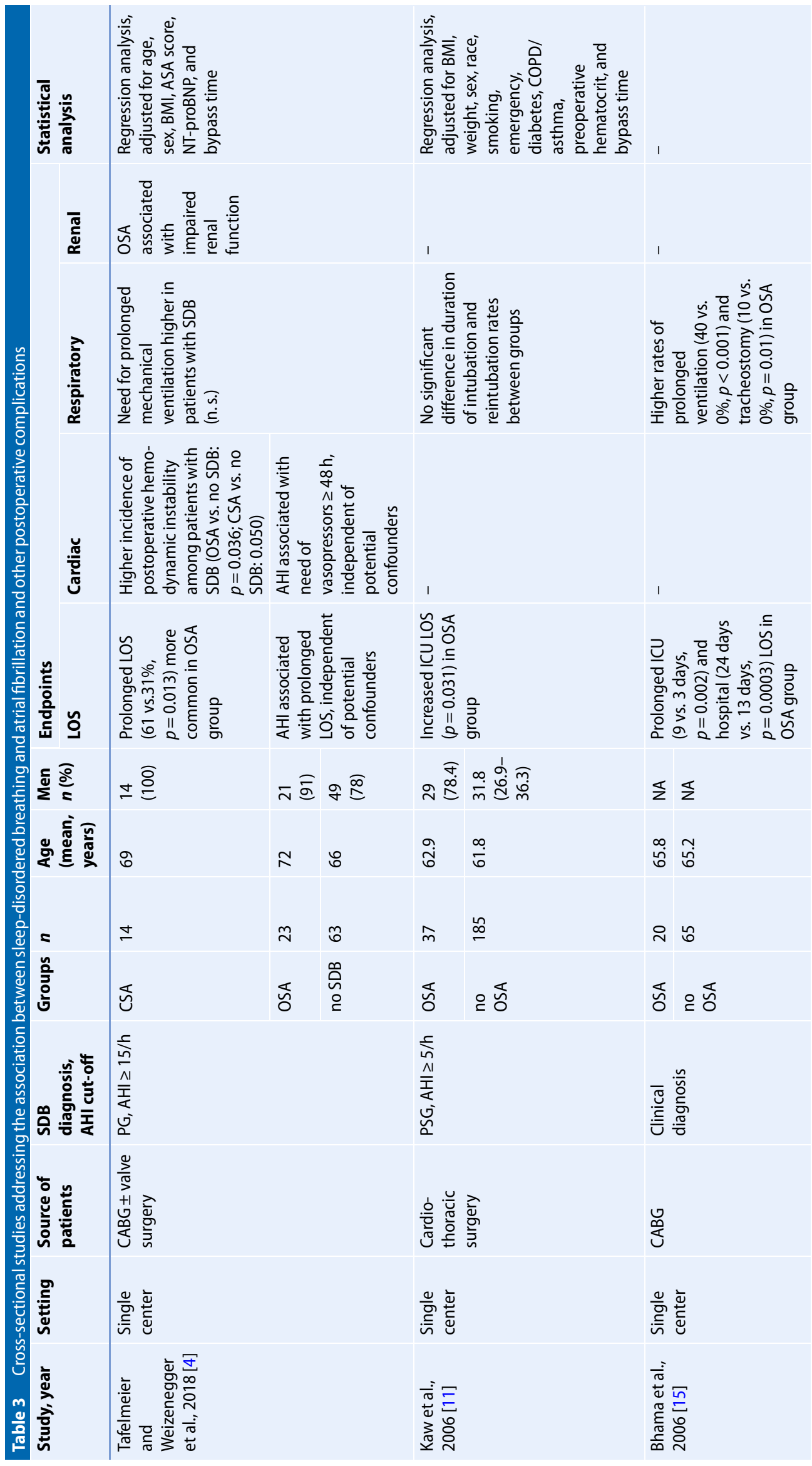




\section{Original studies}

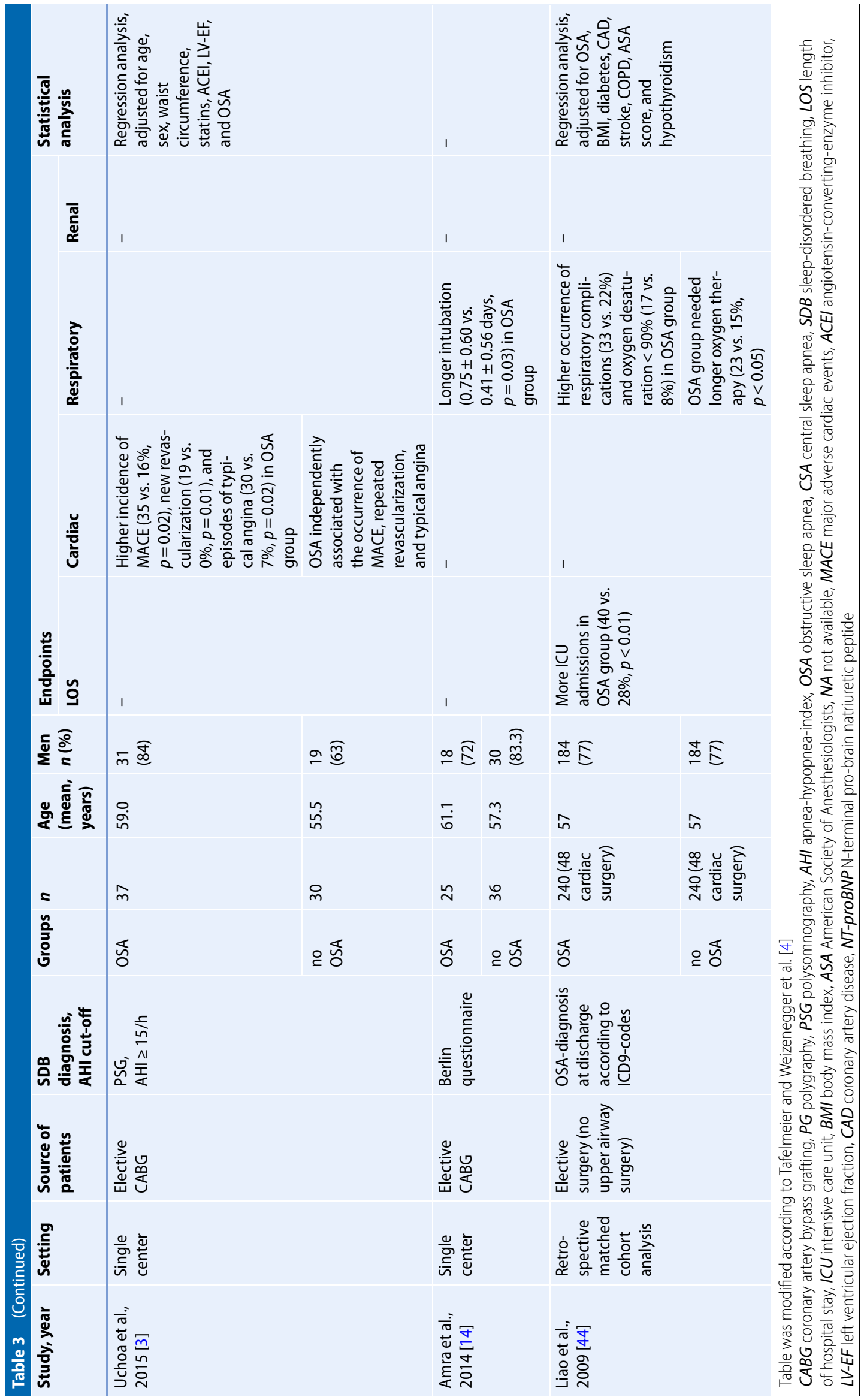


and prevalence estimates for CSA among patients with chronic heart failure vary between 30 and 50\% [41]. Therefore, our study will complement previous research by differentiating between OSA and CSA and thus offer a more comprehensive assessment of SDB and its subtypes on postoperative outcome.

Though polysomnography is considered the gold standard for diagnosing SDB, portable SDB monitoring is used in this study. Consistent with routine clinical practice, the type of SDB is assessed by the frequency of obstructive and central apneas per hour of sleep. As measurements of nasal flow, pulse oximetry, and thoracic breathing effort are methodologically similar in portable SDB monitoring and polysomnography, there is no major difference in the discrimination between obstructive and central apneas.

For a more precise discrimination between OSA and CSA, hypopneas need to be classified into their obstructive and central nature [42-44]. This is not feasible with portable SDB monitoring, since sleep stages are not assessed by electroencephalography and an abdominal effort band and a snore microphone are not available to detect paradoxical breathing and snoring. Moreover, total sleep time is not measured during portable SDB monitoring.

To ensure a consistently high quality of SDB monitoring and low failure rates, the portable SDB monitoring device and its sensors are attached to the patient by trained medical staff. The quality of the SDB monitoring is considered adequate with at least $4 \mathrm{~h}$ of acceptable scored recordings that include pulse oximetry, nasal flow, and thoracic breathing effort. Hence, for feasibility reasons within our sizable patient cohort undergoing cardiac surgery the following day, the Alice NightOne devices represented a valid alternative to polysomnography.

\section{Conclusion and perspectives}

The present prospective observational study is needed to identify specific risks and risk populations in cardiac surgery. Data gathered by the CONSIDER AF study may facilitate identification of patients at a high-risk for an adverse outcome after cardiac surgery and contribute to the body of knowledge in the area of postoperative complications and SDB. In addition, CONSIDER AF has the potential to generate rational hypotheses regarding the peri- and postoperative management of patients with SDB to be tested in future randomized clinical trials. Based on this knowledge, the peri- and postoperative management of patients with SDB may be optimized to further minimize the rate of postoperative complications.

\section{Corresponding address}

\section{Dr. Maria Tafelmeier, MD}

Department of Internal Medicine II (Cardiology, Pneumology, and Intensive (are), University Medical Center Regensburg

Franz-Josef-Strauss-Allee 11, 93053 Regensburg, Germany

maria.tafelmeier@ukr.de

Author contributions. Maria Tafelmeier, Stefan Wagner, and Michael Arzt were involved in conception, hypotheses delineation, and design of the study; acquisition, analysis, and interpretation of the data; writing and revising the article prior to submission. Marvin Knapp and Simon Lebek were involved in data collection and interpretation, and in revision of the article prior to submission. Florian Zeman was involved in statistical analysis and interpretation, and in the critical revision of the article prior to submission. Bernhard Floerchinger, Daniele Camboni, Marcus Creutzenberg, Sigrid Wittmann, Christof Schmid, and Lars S. Maier were involved in data interpretation and revision of the article prior to submission. Maria Tafelmeier and Michael Arzt are the guarantors of the paper, taking responsibility for the integrity of the work as a whole, from inception to publication.

Funding. This study was supported by grants provided by Philips Respironics and the Medical Faculty of the University of Regensburg.

\section{Compliance with ethical guidelines}

Conflict of interest. M. Tafelmeier, M. Knapp, S. Lebek, B. Floerchinger, D. Camboni, S. Wittmann, M. Creutzenberg, F. Zeman, C. Schmid, L.S. Maier, S. Wagner, and M. Arzt declare that they have no competing interests.

All procedures performed in studies involving human participants are in accordance with the ethical standards of the institutional and/or national research committee and with the 1975 Helsinki declaration and its later amendments or comparable ethical standards. Informed consent is obtained from all individual participants included in the study.
Open Access. This article is distributed under the terms of the Creative Commons Attribution 4.0 International License (http://creativecommons.org/licenses/by/ 4.0/), which permits unrestricted use, distribution, and reproduction in any medium, provided you give appropriate credit to the original author(s) and the source, provide a link to the Creative Commons license, and indicate if changes were made.

\section{References}

1. Heinzer R, Vat $S$, Marques-Vidal $P$ et al (2015) Prevalence of sleep-disordered breathing in the general population: the HypnoLaus study. Lancet RespirMed 3:310-318

2. Danzi-Soares NJ, Genta PR, Nerbass FB et al (2012) Obstructive sleep apnea is common among patients referred for coronary artery bypass grafting and can be diagnosed by portable monitoring. Coron Artery Dis 23:31-38

3. Uchoa CHG, Danzi-Soares NJ, Nunes FS et al (2015) Impact of OSA on cardiovascular events after coronary artery bypass surgery. Chest 147:1352-1360

4. Tafelmeier $M$, Weizenegger $T$, Ripfel $S$ et al (2018) Postoperative complications after elective coronary artery bypass grafting surgery in patients with sleep-disordered breathing. Clin Res Cardiol 107(12):1148-1159. https://doi.org/10.1007/ s00392-018-1289-0

5. Arzt M, Woehrle H, Oldenburg $\mathrm{O}$ et al (2016) Prevalence and predictors of sleep-disordered breathing in patients with stable chronic heart failure: the SchlaHF registry. Jacc Heart Fail 4:116-125

6. Arzt M, Oldenburg O, Graml A et al (2017) Phenotyping of sleep-disordered breathing in patients with chronic heart failure with reduced ejection fraction-the SchlaHF registry. J Am Heart Assoc 6(12). pii:e005899. https://doi.org/10.1161/ JAHA.116.005899

7. Beckmann A, Funkat AK, Lewandowski J et al (2015) Cardiac surgery in Germany during 2014: a report on behalf of the German Society for Thoracic and Cardiovascular Surgery. Thorac Cardiovasc Surg 63:258-269

8. Javaheri S, Parker TJ, Liming JD et al (1998) Sleep apnea in 81 ambulatory male patients with stable heart failure. Types and their prevalences, consequences, and presentations. Circulation 97:2154-2159

9. Memtsoudis S, Liu SS, Ma Y et al (2011) Perioperative pulmonary outcomes in patients with sleep apnea after noncardiac surgery. Anesth Analg 112:113-121

10. Kaw R, Pasupuleti V, Walker E, Ramaswamy A, Foldvary-Schafer N (2012) Postoperative complications in patients with obstructive sleep apnea. Chest 141:436-441

11. Kaw R, Golish J, Ghamande S, Burgess R, Foldvary $\mathrm{N}$, Walker $\mathrm{E}$ (2006) Incremental risk of obstructive sleep apnea on cardiac surgical outcomes. JCardiovasc Surg (torino) 47:683-689

12. Gupta RM, Parvizi J, Hanssen AD, Gay PC (2001) Postoperative complications in patients with obstructive sleep apnea syndrome undergoing hip or knee replacement: a case-control study. Mayo Clin Proc 76:897-905

13. Roggenbach J, Klamann M, von Haken R, Bruckner T, Karck M, Hofer S (2014) Sleep-disordered breathing is a risk factor for delirium after cardiac surgery: a prospective cohort study. Crit Care 18:477 
14. Amra B, Niknam N, Sadeghi MM, Rabbani M, Fietze I, Penzel T (2014) Obstructive sleep apnea and postoperative complications in patients undergoing coronary artery bypass graft surgery: a need for preventive strategies. Int J Prev Med 5:1446-1451

15. Bhama JK, Spagnolo S, Alexander EP, Greenberg M, Trachiotis GD (2006) Coronary revascularization in patients with obstructive sleep apnea syndrome. Heart Surg Forum 9:E813-E817

16. Unosawa S, Sezai A, Akahoshi T et al (2012) Arrhythmia and sleep-disordered breathing in patients undergoing cardiac surgery. J Cardiol 60:61-65

17. Walji S, Peterson RJ, Neis P, DuBroff R, Gray WA, Benge W (1999) Ultra-fast track hospital discharge using conventional cardiac surgical techniques. Ann Thorac Surg 67:363-369 (discussion 9-70)

18. Schweickert WD, Pohlman MC, Pohlman AS et al (2009) Early physical and occupational therapy in mechanically ventilated, critically ill patients: a randomised controlled trial. Lancet 373:1874-1882

19. Taskforce DAS, Baron R, Binder A et al (2015) Evidence and consensus based guideline for the management of delirium, analgesia, and sedation in intensive care medicine. Revision 2015 (DASGuideline 2015)—short version. Ger Med Sci 13:Doc19

20. Arumugam S, El-Menyar A, Al-Hassani A et al (2017) Delirium in the intensive care unit.J Emerg Trauma Shock 10:37-46

21. Thygesen K, Alpert JS, Jaffe AS et al (2012) Third universal definition of myocardial infarction. Eur Heart J33:2551-2567

22. Easton JD, Saver JL, Albers GW et al (2009) Definition and evaluation of transient ischemic attack: a scientific statement for healthcare professionals from the American Heart Association/American Stroke Association Stroke Council; Council on Cardiovascular Surgery and Anesthesia; Council on Cardiovascular Radiology and Intervention; Council on Cardiovascular Nursing; and the Interdisciplinary Council on Peripheral Vascular Disease. Stroke 40:2276-2293 (The American Academy of Neurology affirms the value of this statement as an educational tool for neurologists)

23. Spertus J, Dorian P, Bubien R et al (2011) Development and validation of the Atrial Fibrillation Effect on QualiTy-of-Life (AFEQT) questionnaire in patients with atrial fibrillation. Circ Arrhythm Electrophysiol 4:15-25

24. Kim JA, Lee JJ (2006) Preoperative predictors of difficult intubation in patients with obstructive sleep apnea syndrome. Can J Anaesth 53:393-397

25. Force ADT, Ranieri VM, Rubenfeld GD et al (2012) Acute respiratory distress syndrome: the Berlin Definition. JAMA 307:2526-2533

26. Januzzi JL, Lewandrowski K, MacGillivray TE et al (2002) A comparison of cardiac troponin $T$ and creatine kinase-MB for patient evaluation after cardiac surgery. J Am Coll Cardiol 39:1518-1523

27. Mohammed AA, Agnihotri AK, van Kimmenade RR et al (2009) Prospective, comprehensive assessment of cardiac troponin T testing after coronary artery bypass graft surgery. Circulation 120:843-850

28. Section 2 (2012) AKI Definition. Kidney international supplements 2(1):19-36. Epub 2012/03/01. https://doi.org/10.1038/kisup.2011.32

29. Ely EW, Inouye SK, Bernard GR et al (2001) Delirium in mechanically ventilated patients: validity and reliability of the Confusion Assessment Method for the Intensive Care Unit (CAM-ICU). JAMA 286:2703-2710

30. Ely EW, Margolin R, Francis J et al (2001) Evaluation of delirium in critically ill patients: validation of the Confusion Assessment Method for the Intensive Care Unit (CAM-ICU). Crit Care Med 29:1370-1379

31. Barr J, Fraser GL, Puntillo K et al (2013) Clinical practice guidelines for the management of pain agitation, and delirium in adult patients in the intensive care unit. Crit Care Med 41:263-306

32. Sessler CN, Gosnell MS, Grap MJ et al (2002) The Richmond Agitation-Sedation Scale: validity and reliability in adult intensive care unit patients. Am J Respir Crit Care Med 166:1338-1344

33. Ely EW, Truman B, Shintani A etal (2003) Monitoring sedation status over time in ICU patients: reliability and validity of the Richmond Agitation-Sedation Scale (RASS). JAMA 289:2983-2991

34. Brooks RG, Rabin R, De Charro F (2003) The measurement and valuation of health status using EQ-5D: a European perspective :evidence from the EuroQol BIOMED research programme. Kluwer Academic Pub, Dordrecht

35. Spertus JA, Winder JA, Dewhurst TA et al (1995) Development and evaluation of the Seattle Angina Questionnaire: a new functional status measure for coronary artery disease. J Am Coll Cardiol 25:333-341

36. Lebek S, Plossl A, Baier M et al (2018) The novel CaMKII inhibitor GS-680 reduces diastolic SR Ca leak and prevents CaMKII-dependent proarrhythmic activity. J Mol Cell Cardiol 118:159-168

37. Hsieh FY, Bloch DA, Larsen MD (1998) A simple method of sample size calculation for linear and logistic regression. Stat Med 17:1623-1634

38. Flink BJ, Rivelli SK, Cox EA et al (2012) Obstructive sleep apnea and incidence of postoperative delirium after elective knee replacement in the nondemented elderly. Anesthesiology 116:788-796

39. Anter E, Di Biase L, Contreras-Valdes FM et al (2017) Atrial substrate and triggers of paroxysmal atrial fibrillation in patients with obstructive sleep apnea. Circ Arrhythm Electrophysiol 10(11). pii:e005407. https://doi.org/10.1161/CIRCEP.117. 005407

40. Topkara VK, Cheema FH, Kesavaramanujam S et al (2005) Coronary artery bypass grafting in patients with low ejection fraction. Circulation 112:1344-I350

41. Linz D, Fox H, Bitter T et al (2016) Impact of SERVE$\mathrm{HF}$ on management of sleep disordered breathing in heart failure: a call for further studies. Clin Res Cardiol 105:563-570

42. Randerath WJ, Treml M, Priegnitz C, Stieglitz S, Hagmeyer L, Morgenstern C (2013) Evaluation of a noninvasive algorithm for differentiation of obstructive and central hypopneas. Sleep 36:363-368

43. Bradley TD, Logan AG, Kimoff RJ et al (2005) Continuous positive airway pressure for central sleep apnea and heart failure. N Engl J Med 353:2025-2033

44. Cowie MR, Woehrle H, Wegscheider K et al (2015) Adaptive Servo-Ventilation for Central Sleep Apnea in Systolic Heart Failure. N Engl J Med 373:1095-1105

\section{Verbesserung der Lehre im PJ}

Viele Mediziner haben wenig positive Erinnerungen an ihr Praktisches Jahr (PJ) des Medizinstudiums. Auch für die Kliniken ist hinsichtlich der Ressource "Zeit" die Einbindung der medizinischen Lehre oft schwierig, es entstehen für beide Seiten unerfreuliche und konfliktträchtige Situationen. Zusätzlich ist an vielen Einrichtungen zum Teil eine deutliche Diskrepanz zwischen der Fremdeinschätzung durch die Studierenden und der Selbsteinschätzung der Lehrstuhlinhaber und ihrer Lehrbeauftragten zur Qualität ihrer Lehre festzustellen.

Um den PJ-Studierenden dauerhaft Lehre auf hohem Niveau zu bieten und die Lehrenden zu unterstützen, hat die Medizinische Fakultät der Universität des Saarlandes UdS 2016 ein Zehn-PunkteProgramm an Sofortmaßnahmen zu Verbesserung der PJ-Lehre aufgestellt und erfolgreich eine PJ-Faculty etabliert. Dies hat an der gesamten Fakultät zu einem deutlichen Motivationsschub geführt und garantiert deren Nachhaltigkeit.

In Ausgabe 1/19 von Der Ophthalmologe wird das Zehn-Punkte-Programm ausführlich vorgestellt, das sich auch auf andere Standorte und Einrichtungen übertragen lässt. Der Beitrag ist frei zugänglich.

Literatur:

Seitz, B., Graf, N., Menger, M. et al. (2019) Etablierung einer PJ-Faculty an der Medizinischen Fakultät der Universität des Saarlandes UdS. „Docendo discimus", , "Transparenz und Kommunikation". Ophthalmologe116: 28-32

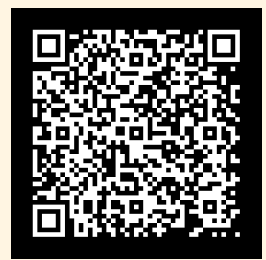

